\title{
GESTÃO DA QUALIDADE DO SETOR CALÇADISTA: UM ESTUDO SOBRE O PERFIL DAS EMPRESAS BRASILEIRAS
}

Sandro A. T. de Mendonça Doutor em Ciências da Engenharia Ambiental pela Universidade de São Paulo (USP). Mestre em Conservação e Manejo de Recursos pela Universidade Estadual Paulista Júlio de Mesquita Filho (UNESP).

Natalia Sander Larios

Graduada em Administração (FATEB).

\section{RESUMO}

A indústria calçadista brasileira se esforça para mudar o perfil de sua gestão e paulatinamente passa a aderir a novos processos de produção, como a Gestão da Qualidade. Tal gestão tem permitido a sobrevivência das empresas deste setor. Desta forma, as empresas calçadistas podem competir no mercado doméstico orientado pela Gestão da Qualidade como um diferencial competitivo e dessa maneira forja sua imagem corporativa. A partir de Pesquisa Bibliográfica identificou-se que historicamente o setor calçadista brasileiro pratica um modelo tradicional de produção, podendo até ser comparado ao modelo fordista; o que é considerado um entreve para o desenvolvimento e crescimento do setor. Por isso, as empresas calçadistas buscam a certificação da qualidade, investindo na qualificação de seus trabalhadores e aderem a novas tecnologias impostas pelo mercado consumidor.

Palavras Chaves: Perfil do setor calçadista brasileiro; Certificação de qualidade; Modelo Americano; Competitividade organizacional, Imagem corporativa.

\section{ABSTRACT}

The Brazilian footwear industry strives to change the profile of their management and gradually passes to adhere to new production processes, such as Quality Management. Such management has allowed the survival of businesses in this sector. Thus, the footwear companies can compete in the domestic market driven quality management as a competitive advantage and thus forging your corporate image. From Library Research identified that historically the Brazilian footwear industry practice a traditional style of production and can even be compared to the Fordist model, which is considered a glimpse into the development and growth of the sector. Therefore, the footwear companies seeking certification of quality by investing in the training of their workers and adhere to new technologies imposed by the market.

Key Words: Profile of the Brazilian footwear industry; Quality Certification, American Model, Organizational competitiveness and corporate image. 


\section{ADMINISTRAÇÃO DE EMPRESAS EM REVISTA}

\section{INTRODUÇÃo}

A indústria brasileira de calçado pertence há um setor considerado tradicional, podendo ser comparado ao modelo de produção fordista, onde os funcionários se posicionavam ao longo de uma esteira e com o tempo cronometrado exercem funções específicas durante a jornada de trabalho. Com o tempo, esse modelo de produção se descaracterizou, pois o ritmo de produção individual se adaptou as necessidades do trabalhador e, por conseguinte, tornou-se mais lucrativo para o empresário.

Dessa forma, a qualificação dos funcionários e a preocupação com o método de produção se tornaram prioridade para o setor calçadista, convergindo a favor da Gestão da Qualidade.

A Gestão da Qualidade tem por objetivo aprimorar o aprendizado contínuo do trabalhador dentro das empresas, tanto para aqueles que cumprem uma tarefa simples ou para aqueles que cumprem uma tarefa complexa, objetivando a diminuição de custos e buscar gerar qualidade de vida para os colaboradores.

Embora o setor calçadista brasileiro possua tecnologias semelhantes às de países desenvolvidos, ao produzir em grande escala e sem trabalhadores qualificados, sua produção é comparativamente considerada de nível médio quanto a qualificação.

A produção brasileira de calçados tem um grande gargalo em relação à mão de obra e preparação do couro. Ela tem alto índice de rotatividade de funcionários, que interfere significativamente no ritmo de produção. Além disso, o couro brasileiro é considerado sem brilho em relação aos produzidos em outros países, em particular na Itália.

Dessa forma, empresas brasileiras buscam se fundir a empresas multinacionais, tanto para elaboração de estudos como a criação de meios de melhorar o aproveitamento e preparação da matéria prima, incluindo a divulgação internacional de suas marcas, a criação e expansão de franquias.

A imagem do Brasil no exterior interfere sobremaneira nos produtos comercializados externamente. Embora tal imagem seja forjada a partir de práticas esportivas vencedoras e diversão popular, a pobreza também é uma variável presente na composição dessa imagem. Porém, a simpatia que o Brasil exibe a partir de sua cultura nacional de alguma forma favorece os produtos exportados. Entretanto, o que 
na realidade prejudica o Brasil é a falta de uma política de marketing mais intensiva da qual divulgue melhor as marcas, modelos e design dos calçados brasileiros comercializados no exterior.

Outro dado que prejudica o ambiente organizacional brasileiro, em particular o do setor calçadista é que o número de trabalhador qualificado no mercado brasileiro é baixo e os caminhos por onde seguem a Gestão da Qualidade são morosos.

Devido a falta de qualificação do trabalhador e a falta de políticas públicas suficientes para forjar a qualificação desejada, na intenção de eliminar essa defasagem, associações vinculadas ao setor calçadista como é o caso da Abicalçados, instituições sem fins lucrativos como SENAI e SEBRAE e o Governo brasileiro buscam formas de capacitar pessoas que desejam entrar no mercado de trabalho, ensinando os processos de produção do setor calçadista nos moldes da Gestão da Qualidade.

Porém, apenas capacitar os trabalhadores não é o suficiente, o empresário brasileiro deveria entender que após sua qualificação, o funcionário capacitado desejará receber uma remuneração de acordo com o seu grau de capacitação, e se tornará resistente ao chão de fábrica. Assim, será imprescindível que o empresário se adapte a essa nova realidade, passe criar políticas de remuneração salarial mais satisfatória para o trabalhador, incluindo benefícios e incentivos dos quais estimule a permanência do funcionário na indústria calçadista.

Outro gargalo encontrado na produção da indústria de calçados refere-se ao modo de preparação do couro. O sistema utilizado na pecuária tem resultado em um couro com alto índice de defeito ocasionados principalmente por parasitas, corte e marcas nos animais no momento do abate. Inclusive, o couro brasileiro apresenta maior porosidade, menor brilho quando comparado ao couro europeu.

O Brasil utiliza tecnologias semelhantes a da Itália e estudam meios de fundir os processos de produção italiana no Brasil, pois se acredita que dessa maneira, o calçado brasileiro pode elevar seu nível de qualidade de forma significativa.

Contudo, não se pode deixar de notar que a imagem do Brasil no exterior afeta de alguma forma a competitividade das empresas brasileira na exportação. O que de certa forma influência na imagem de seus produtos exportados. Além de prevalecer que os produtos de países em desenvolvimento são assimilados a uma imagem não catalisadora de qualidade. 


\section{ADMINISTRAÇÃO DE EMPRESAS EM REVISTA}

CENTRO UNIVERSITÁRIO CURITIBA - UNICURITIBA - VOLUME 19 - NÚMERO 01/2019 -CURITIBA/PARANÁ/BRASIL - PÁGINAS 97 A 122 - DOI: 10.6084/m9.figshare.11338463 - ISSN: $2316-7548$

Pesquisas realizadas durante os anos de 2001, 2004 e 2013 indicam que essa imagem que se têm sobre o setor calçadista estaria mudando, e que os produtos brasileiros passariam a catalisar outra imagem, mais favorável ao que se espera com a Gestão da Qualidade.

\section{REVISÃO DE LITERATURA}

Em 1824 com a chegada dos primeiros imigrantes alemães no Brasil iniciou-se a produção de calçados no Rio Grande do Sul, na cidade do Vale do Rio dos Sinos, era uma produção artesanal e caseira, só em 1888 foi aberta a primeira fábrica de calçados nessa região (ABICALÇADOS, 2013).

A concentração das empresas de grande porte está localizada no estado do Rio Grande do Sul, a produção brasileira de calçados está sendo distribuída para outros polos, como nas regiões do Sudeste e Nordeste do país, sendo destacado o interior do estado de São Paulo com as cidades de Jaú, Franca e Birigui, e estados emergentes como Paraíba, Ceará e Bahia. Também há crescimento na produção no estado de Santa Catarina na região de São João Batista e em Minas Gerais na região de Nova Serrana e Belo Horizonte (SINDICALÇADOS, 2008).

A indústria calçadista desempenha importante papel na economia brasileira no que se diz respeito à empregabilidade, de sete milhões de pessoas ocupadas assalariadas na indústria de transformação no Brasil em 2007, gerando cerca de 300 mil empregos, o que significa um percentual de $4,3 \%$ de toda a indústria de transformação (ABICALÇADOS, 2013).

O Brasil tem representado um importante papel na história do calçado, é o maior país da América Latina e um dos mais destacados fabricantes de manufaturas do couro, sendo no ranking o terceiro dos maiores produtores mundiais, com uma participação diferenciada no setor de calçados femininos que representam qualidade e preços competitivos. A capacidade produtiva da indústria de calçado é estimada em cerca de 800 milhões de pares de calçados/ano, dos quais 70\% são destinados ao mercado interno e 30\%, à exportação (FRANCISCHINI e AZEVEDO, 2003). 


\section{ADMINISTRAÇÃO DE EMPRESAS EM REVISTA}

De acordo com Rocha (2002 ${ }^{1}$ apud de DALSOTO, 2007), a primeira grande exportação ocorreu em 1968 tendo como destino os Estados Unidos, fazendo com que o Brasil se destacasse nas exportações de produtos manufaturados.

Segundo os autores supracitados o Brasil é conhecido como exportador de calçados de couro para passeio, especialmente para o público feminino, é importante notar que também é aquele que apresenta maior preço médio por par exportado.

Segundo Azevedo et al. (2009), uma das principais vantagens comparativas brasileiras é a facilidade de disponibilizar matéria-prima a baixo custo, assim sendo, o perfil da produção para exportação tem se voltado para produtos mais intensivos em matéria-prima e processamento.

No mesmo contexto, algumas das tecnologias utilizadas na indústria de calçados italianos deveriam ser usadas pela indústria brasileira, como o Computer Aided Design (CAD) e o Computer Aided Manufacturing (CAM). Essa tecnologia seria eficaz para a indústria, como na redução de perda de matéria-prima, aumento da qualidade, na redução de produtos químicos e um melhor método no tratamento de efluentes (FRANCISCHINI e AZEVEDO, 2003).

Segundo Azevedo et al. (2009), além de tratar de uma importante estratégia para resolução do problema da qualidade do couro brasileiro. O sistema de produção usado na pecuária tem resultado em um couro com elevada incidência de defeitos, ocasionados principalmente por parasitas, cortes e outras marcas nos animais no momento do abate, somando ao fato de prevalecer no Brasil o abate de animais mais velhos.

Na década de 1990, o setor calçadista passou por mudanças importantíssimas que mudaram as transformações no ambiente competitivo, decorrente de mudanças institucionais, macroeconômicas e da concorrência internacional. Entre as principais mudanças institucionais estão dois importantes fatos: o processo de abertura comercial e a Constituição de 1988 (FRANCISCHINI e AZEVEDO, 2003).

Segundo autores supracitados entre os anos de 1994 e 1998, os principais aspectos que modificam os padrões de concorrência interna no país são a abertura do mercado e a valorização do Real, já que produtos importados apresentam menores

1 ROCHA, A. A internacionalização das empresas brasileiras: estudo de gestão internacional. Rio de Janeiro: Mauad, 2002. 


\section{ADMINISTRAÇÃO DE EMPRESAS EM REVISTA}

preços no país. Dessa forma as empresas se adaptaram as estratégias que apresentam flexibilidade nas atividades de produção, para atender rapidamente padrões de demanda que podem ser modificados inesperadamente.

Conforme Gremaud et. al. (2002), a Constituição de 1988 trouxe como principal dificuldade para o setor calçadista brasileiiro o aumento dos impostos para estados e municípios. Ainda, a constituição comprometeu o desenvolvimento de uma política industrial centralizada.

Assim uma importante estratégia verificada no setor calçadista foi a transferências de unidades de produção para o Nordeste. Estas empresas buscam menores custos de produção, principalmente custos de mão de obra e incentivos fiscais (FRANCISCHINI e AZEVEDO, 2003).

Segundo autores supracitados as regiões Sul e Sudeste não deixaram de ser importantes, pois neles continuaram concentradas as linhas de produção sofisticadas, o gerenciamento da atividade produtiva, a concepção e as atividades de design dos calçados e desenvolvimento de produtos.

Tais estratégias se destacam nos aspectos ligados a comercialização de produtos e a especialização do segmento, esta estratégia competitiva tem como objetivo principal a redução dos custos produtivos e o desenvolvimento de maior agilidade para responder eventuais modificações na demanda (Idem).

As empresas do setor calçadista sofreram um estreitamento de seus espaços de atuação, assim sendo, principalmente por dois fatos: o primeiro, elevação da qualidade de calçados chineses; e o segundo, redução dos custos de produção da Itália (GORINI, 1998).

O novo ambiente competitivo exige das empresas a capacidade de adotar estratégias tecnológicas com o objetivo de melhorar a sua qualidade, é evidente que comparado com produtores internacionais de primeira linha, o setor nacional apresenta algumas defasagens nos processos produtivo e tecnológico, mas não ha nível de determinar um ponto de estrangulamento da produção (CARVALHO JUNIOR, 1984). 


\section{ADMINISTRAÇÃO DE EMPRESAS EM REVISTA}

De acordo com Barbieri (1986² apud de REIS, 2010), é possível reafirmar que os problemas do setor calçadista brasileiro, no momento atual, são de caráter estritamente conjuntural e se originaram na crise global da economia. Em uma perspectiva de médio para longo prazo o setor calçadista se fortalecerá competitivamente em termos de mercados internos e externos, sendo necessária uma redefinição dos seus processos produtivos, orientando-se para a incorporação de progresso técnico e inovações tecnológicas, de maneira a aproximar-se dos seus parceiros a nível internacional.

Diversos setores industriais começaram a se preocupar com o aprimoramento dos processos produtivos após a Revolução Industrial, onde foram adotados os controles estatísticos de qualidade. E com o fim da Segunda Guerra Mundial, as indústrias começaram a organizar inspeções onde perceberam que os produtos apresentados ao mercado não eram suficientes para tratar de qualidade (CROSBY, 1990).

O conceito básico de qualidade e melhoria continua refere-se à adequação ao uso de defeitos. As organizações precisam produzir produtos e serviços em condições satisfatórias para os usuários finais, sob todos os aspectos. A expressão bom, bonito e barato refere-se simplesmente a essa necessidade (MIRANDA, 1994).

A qualidade total possui três bases importantes: A primeira refere-se às ferramentas e técnicas que os colaboradores aprendem a utilizar, a segunda considera o cliente como foco e, a terceira preocupa-se com a cultura da organização, sendo um facilitador na busca constante da satisfação do consumidor através de um programa onde se abrange ferramentas, técnicas e treinamentos, o que contribui para um processo crescente dentro da empresa que faz com que os produtos e serviços sejam de alta qualidade (SASHKIN e KISER, 1994).

Segundo Miranda (1994, p.5), "Durante muitos anos, a maximização da qualidade foi associada à maximização de custos e preços. $O$ que se persegue e consegue, hoje, é maximizar a qualidade ao mesmo tempo em que se minimizam os custos".

2 BARBIERI, T. Aspectos do problema de distribuição no setor de calçados. São Paulo: FEA, 1986. 


\section{ADMINISTRAÇÃO DE EMPRESAS EM REVISTA}

De acordo com Lowrey et. al. (2000), existem dois tipos de treinamentos importantes, os de habilidades e os de cruzamentos. O treinamento de habilidade aumenta a satisfação do funcionário assim gerando um aumento na qualidade do produto, enquanto o cruzado faz com que os funcionários fiquem mais versáteis e flexíveis, sendo crucial para a organização.

Dentro dessa filosofia, empresas brasileiras e de todo o mundo passaram a introduzir, de maneira correta, os sistemas participativos de gestão da qualidade total como um objetivo de aumentar a sua produtividade reduzindo custos (RELATÓRIO CNPQ, 2010).

Para Campos (1992), a introdução do programa de qualidade total nada mais é que elementos de várias fontes, que envolve método cartesiano, controle estatístico de processos, conceitos sobre o comportamento humano lançado por Maslow, ênfase nas tarefas pregadas por Taylor e, principalmente os conceitos e experiências de Juran.

Por isso que a qualidade total pode ser entendida como, o controle exercido por todas as pessoas, para a necessidade de outras pessoas (CAMPOS, 1992).

O modelo tradicional de produção no setor calçadista pode ser comparado às características do modelo fordista que é baseado em máquinas e tarefas dedicadas a produção em massa objetivando ganhos de escala. Os funcionários se colocam ao longo de esteiras de acordo com a suas especializações e passam a ter uma jornada de trabalho diária repetindo a mesma tarefa, em um período cronometrado (BIEHL e MOSELE, 2003).

Essa condição de trabalho padronizado acaba por restringir a iniciativa e a criatividade do trabalhador. Visualizando apenas a sua pequena participação no processo de produção de calçados, o operário tem por fim o seu potencial de contribuição para melhorias na indústria calçadista desperdiçado, transformando a jornada de trabalho num momento mecanizado, não atrativo e cansativo (Idem).

A gestão da qualidade total tem por objetivo buscar o aprendizado continuo, seja numa tarefa simples ou extremamente complexa, tendo por finalidade reduzir as surpresas desagradáveis diminuindo custos e buscando qualidade de vida. É através da gestão da qualidade que os empresários exercem um trabalho continuo, desenvolvendo um processo de conhecimento e educação que visa à melhoria da 


\section{ADMINISTRAÇÃO DE EMPRESAS EM REVISTA}

CENTRO UNIVERSITÁRIO CURITIBA - UNICURITIBA - VOLUME 19 - NÚMERO 01/2019 -CURITIBA/PARANÁ/BRASIL - PÁGINAS 97 A 122 - DOI: 10.6084/m9.figshare.11338463 - ISSN: $2316-7548$

qualidade de vida tanto dos colaboradores internos como externos (BANAS QUALIDADE, 2008).

A utilização desse processo dentro da organização gera recursos dos quais os resultados são diretamente voltados aos seus clientes e colaboradores (GONÇALVES, 2000).

Alguns princípios da gestão da qualidade desenvolvidos por Willian Edward Deming, aceitos nas empresas americanas, após serem aplicados no Japão e que posteriormente são bases de referências que ajudam a ingressar no processo da gestão da qualidade são: 1) Adotar nova filosofia, assumindo desafios, conscientizarse de suas responsabilidades e assumir a liderança em direção à transformação; 2) Eliminar a necessidade de inspeção em massa, priorizando a internalização da qualidade do produto; 3) Minimizar os custos totais, tendo um único fornecedor para cada item, desenvolvendo relacionamentos calcados na confiança; 4) Aperfeiçoar constante e continuamente todo o processo de planejamento, com objetivo de aumentar a qualidade e produtividade; 5) Fornecer treinamento aos funcionários, estabelecer um programa de educação e autoaperfeiçoamento; 6) Eliminar padrões artificiais para o chão de fábrica; 7) Abolir avaliação de desempenho, os trabalhadores tem que ter orgulho de seu trabalho e não serem comparados um com os outros causando constrangimentos; 8) Colocar todos da empresa para trabalhar de modo a realizar a transformação dentro da organização (BANAS QUALIDADE, 2008).

Segundo Graham e Lebaron (1994³ apud de SETANIN, 2003), entende-se que os diversos tipos de atividades empresariais que envolvem os processos são apenas inter-relacionados, assim sendo, eles definem que a coordenação é a essência do processo desenvolvendo suas atividades.

De acordo com Miranda (1994, p.15) o Controle de processos nada mais é que um controle na forma de prevenir inspeções:

O controle estatístico de processo baseia-se na utilização de conceitos administrativos e estatísticos consubstanciados na forma de cartas de controle e procedimentos operacionais. Sua aplicação na área de controle da qualidade permite a eliminação da dependência de inspeção dos produtos acabados, visto que a ocorrência de desvios passa a ser atacada preventivamente.

\footnotetext{
${ }^{3}$ GRAHAM, M.; LEBARON, M. The horizontal revolution. San Francisco: L Jossey-Bass, 1994.
} 


\section{ADMINISTRAÇÃO DE EMPRESAS EM REVISTA}

Em um sentido amplo, CAMERON et. al. (1995 apud de GONÇALVES, 2000) define que os processos de trabalho são maneiras de se realizar um conjunto determinado de tarefas, sob um ponto de vista especial envolvendo todos da organização para que trabalhem harmoniosamente de forma a prosseguir constantemente na busca pela excelência.

De acordo com Gonçalves (2000), analisar os processos coordenados em vez de fluxos físicos de materiais ou produtos, tem sido a abordagem da engenharia na gestão qualidade total.

Dessa maneira a definição de processos não inclui apenas tarefas executadas, como também seu numero de colaboradores, a divisão do trabalho e a tecnologia utilizada, assim, os indicadores de eficiência e os resultados esperado são definidos através desse método de trabalho (Idem).

Alguns métodos de trabalhos refere-se à qualificação e especialização dos funcionários, nesse sentido, além da necessidade de cortar custos de produção o empresário brasileiro do setor calçadista advoga a reestruturação do sistema educacional, o que em sua opinião, são condições indispensáveis para o crescimento industrial da empresa, pois também aumenta a oferta por pessoal mais capacitado (OLIVEIRA, 2003).

Ao contrário do que se pode imaginar, a produção em grandes quantidades produzidas pelas empresas calçadistas requer tempo, o que ocasiona o desinteresse dentro das indústrias para qualificar os operários, pois o treinamento de funcionários é considerado como custo. Por esta razão, a mão de obra é desqualificada o que gera a alta rotatividade, levando a substituição no preenchimento do quadro de funcionários com alguém de fora da empresa (BIEHL e MOSELE, 2003).

$\mathrm{Na}$ busca de suprir essa dependência por mão de obra qualificada o Serviço Nacional de Aprendizagem Industrial (SENAI) e outras instituições privadas brasileiras sem fins lucrativos, vinculadas à indústria calçadista buscam oferecer atividades e cursos de qualificação profissional em diversos setores das indústrias calçadistas (FIEPB, 2013).

\footnotetext{
${ }^{4}$ CAMERON, K. S.; FREEMAN, S. J.; MISHRA, A. K. Downsizing and redesigning organizations. In: HUBER, G.; GLICK, W. Organizational change and redesign. New York: Oxford, 1995.
} 


\section{ADMINISTRAÇÃO DE EMPRESAS EM REVISTA}

Dessa forma, uma estratégia encontrada pelos empresários das indústrias de calçado no Brasil é oferecer oportunidades de capacitação juntamente com o apoio dos sindicatos, governo e associações vinculadas ao ramo do setor calçadista como a Abicalçados. Acreditando que a formação educacional das pessoas seja um ponto inicial para a resolução do problema enfrentado pela alta rotatividade (ABICALÇADOS, 2013).

Desde o inicio do século XXI, não se pode mais considerar a gestão da qualidade total como sendo uma função isolada ou apenas um diferencial no mercado competitivo. Os clientes tornaram-se mais exigentes e conscientes, fazendo não só com que a qualidade seja um meio de sobrevivência para a organização, como também um recurso de qualidade de vida para os funcionários da empresa (BLÖDORN, e SOARES, 2011).

A gestão da qualidade pode ser divida em dois termos, a qualidade humana que diz respeito à satisfação e desejos emocionais, tais como: comprometimento, credibilidade, consistência e lealdade tanto dos clientes ou dos funcionários. Ou, da qualidade técnica que é voltada a satisfazer as exigências e expectativas concretas, tais como: tempo de produção, taxa de defeito, funcionabilidade, durabilidade, segurança e garantia (idem).

Torna-se necessário que as empresas unem essas definições técnicas e humanas da qualidade total, para que possam buscar a excelência, pois uma empresa excelente é uma empresa que consegue sobreviver. $E$ para que possa sobreviver à organização tem que ser competitiva. E só se consegue adquirir a competitividade através da gestão da qualidade (BLÖDORN e SOARES, 2011).

Neste sentido, em função de desenvolver recursos disponíveis, como: financeiros, pessoal capacitado e estratégias de atuação no mercado externo, que esta cada vez mais exigente, os programas de qualidade têm como objetivo estimular novos conceitos de competitividade e produtividade, na concepção de adquirir elevados níveis da qualidade na produção, às empresas vem gerando grandes esforços para continuarem no mercado competitivo que está cada vez mais disputado (SCHEFER, 2010).

Nesta condição uma das principais vantagens comparativas brasileiras, é a disponibilidade de matéria prima a baixo custo, assim, o perfil da produção para 
exportação tem se voltado intensivamente em matéria-prima e processamentos da mesma (FRANCISHINI e AZEVEDO, 2003).

O Brasil utiliza tecnologias semelhantes às tecnologias utilizadas na região da Toscana (Itália), a diferença entre a produção italiana da produção brasileira é que o Brasil produz em grande escala. Assim, a qualidade dos produtos brasileiros é considerada pelos italianos sendo como de nível médio (ABICALÇADOS, 2013). Uma característica que difere o couro brasileiro apresentado é a maior porosidade e menor brilho, quando comparado com o couro europeu, característica comparativa ao Italian Look, que privilegia o brilho desse material (FRANCISHINI e AZEVEDO, 2003).

Segundo a Abicalçados (2013), um grande beneficio conquistado pelo Brasil é a forma que esta sendo estudada como difundir o trabalho italiano no Brasil, na busca de parcerias comerciais, o presidente e o diretor da Associazione Conciatori Sante Crose sull'Arno, Franco Donati e Pieto Maccanti, marcaram presença na 45ํㅡㄹ Francal realizada no primeiro semestre de 2013 em São Paulo. Os dirigentes acreditam que com a matéria prima italiana, o calçado brasileiro pode elevar a sua qualidade de forma significativa, incluindo o melhoramento em seu design.

Segundo os indicadores nacionais que são relativos à qualidade $e$ produtividade, há um avanço em curto prazo referente à qualidade das indústrias brasileiras que cresceram $37 \%$ nos últimos cinco anos, de acordo com pesquisa realizada no ano de 2008 pelo Instituto Brasileiro de Geografia e Estatística (IBGE) (SCHEFER, 2010).

O autor supracitado, ainda relata que o empresário brasileiro que teve que aprender a sobreviver com índices inflacionários altos, teve também que aprender a conviver com a estabilidade e com a competição do mercado. Segundo a pesquisa feita pelo IBGE, realizada no ano de 2008, o índice de retrabalho das indústrias que antes era de $30 \%$ no ano de 1990 , caiu para 3,7\%, e aproximando-se da média mundial que é de $2 \%$. O que ainda indica que o Brasil precisa melhorar a sua forma de produção em massa, procurando formas mais eficientes para valorizar o brilho e textura do couro e de outras matérias primas, como é o caso do material sintético.

A visão de que a qualidade estaria restrita em relação às melhorias localizadas demonstra que os esforços para minimizar defeitos são cada vez mais presentes nas organizações (CARVALHO e PALADINI, 2005). Inclusive, conforme o gerenciamento 


\section{ADMINISTRAÇÃO DE EMPRESAS EM REVISTA}

e rotina são implantados nas empresas os índices de defeitos caem e as especificações podem ser obedecidas integralmente (CAMPOS, 1992).

Dessa forma, as empresas do setor calçadista aderem esse benéfico na busca por certificações, como a ISO 9000 que possibilita incrementos do nível de organização e controle interno, referente ao aumento da satisfação dos clientes e funcionários (SCHEFER, 2010).

Outra certificação que poderá ser aderida as empresas calçadistas é o Selo de Sustentabilidade, um projeto divulgado pelo Instituto By Brasil e pela Assintecal (Associação Brasileira de Empresas de Componentes para Couro, Calçados e Artefatos), o projeto foi uma parceria entre o Laboratório de Sustentabilidade (Lassu), do Departamento de Engenharia de Computação e Sistemas Digitais da Escola Politécnica (Poli) da USP (SEBRAE, 2012).

Segundo o autor supracitado, o selo de sustentabilidade tem como objetivo ser um diferencial competitivo no mercado nacional e internacional. Ao aspecto econômico, por exemplo, já que a sustentabilidade é uma forma de gestão da qualidade que é voltada ao bem da sociedade em geral, a racionalização do uso da matéria prima, da água e da energia, substituindo as substancia tóxica como o cromo que é usado para amaciar o couro por outras que não prejudiquem a natureza será um diferencial no mercado competitivo. A demanda de produtos brasileiros exportados cresce no decorrer dos anos e querendo que a cadeira consumidora responda a essa demanda o Selo de Sustentabilidade veio como forma da conscientização e beneficiação dos produtos produzidos voltados ao bem estar social da comunidade em geral.

Pode-se notar que os resultados práticos da gestão da qualidade em nível operacional motivam o desenvolvimento dos conceitos táticos da qualidade em si, cujos benefícios criam uma visão estratégica (CARVALHO e PALADINI, 2005).

Um sistema efetivo e bem monitorado assegura que a necessidade do cliente seja satisfatória, garantindo um bom projeto e desempenho, com prazo de entrega preciso, e serviço eficiente, gerando o aumento da confiança do cliente e incorporando credibilidade ao produto final (SCHEFER, 2010).

A garantia da qualidade é uma conquista que a empresa através de uma gestão bem estruturada conseguiu atingir seu potencial, de modo que a qualidade foi exercida 
de forma motivadora. Sendo este um dos grandes benefícios da gestão da qualidade (CAMPOS, 1992).

Assim nota-se algumas empresas calçadistas consideradas de ponta, vêm criando alianças com grandes empresas multinacionais e entidades sem fins lucrativos, no esforço para a atualização de suas tecnologias organizacionais, com objetivo de competir no mercado, na iniciativa de inovação de seus equipamentos (PICCININI, 1995).

Outro exemplo de investimentos que acontece entre empresas do setor calçadista e organizações multinacionais é o caso da empresa Empório Naka, fundada por um casal de imigrantes italianos que montaram uma pequena fábrica de sapatos em São Paulo no ano de 1934. E na sua terceira geração se expandiu adotando um sistema de franquias em 2007, voltada ao segmento feminino. A marca de calçados Empório Naka fechou a venda de 35\% de seu capital com a gestora de investimento portuguesa Lusobrastex, com o intuído de agregar investimentos ao seu desenvolvimento, para a expansão de sua marca na exportação (EXAME, 2012).

O desenvolvimento desses vínculos entre empresas brasileiras e empresas multinacionais destaca o Brasil como um dos melhores países da América do Sul em desempenho de exportação; entretanto, a maior parte da produção brasileira é enviada para os Estados Unidos, Argentina e França (G1, 2013).

Contudo, fabricas de calçados vem investido cada vez mais na qualidade de seus produtos, procurando adquirir a certificação da qualidade de acordo com as especificações da Associação Brasileira de Normas Técnicas (ABNT). O sucesso da adequação dessas normas trás, consequentemente, prosperidade as empresas brasileiras (ABICALÇADOS, 2013).

A International Organization for Standardization (ISO) criou a serie de normas denominadas ISO 9000, cujo objetivo principal foi o sinergismo entre as empresas e os seus clientes para aumentar o nível de satisfação com referência à qualidade, por meio de procedimentos padronizados (BANAS QUALIDADE, 2008).

De acordo com Puri (19945 apud de SILVA et. al., 2008), os processos que são determinantes na certificação da qualidade nas empresas influenciam de modo geral

${ }^{5}$ PURI, S. C. ISO série 9000 certificação: gestão de qualidade total. Rio de Janeiro: Quality mark, 1994. 


\section{ADMINISTRAÇÃO DE EMPRESAS EM REVISTA}

na produtividade, na otimização de material evitando o desperdício de matéria prima, e na satisfação dos clientes. Para cada tipo de certificação existe uma norma ISO, como a série 9000 , que diz respeito ao controle dos produtos ou serviços.

Tal grupo de normas associadas aos calçados brasileiros representa um grande avanço na indústria calçadista no Brasil, mas também revela a existência de um ambiente pouco explorado no mercado (IBTEC, 2009).

O controle de qualidade direto nas pequenas empresas calçadistas é extremamente baixo, e mais expressivo nas medias e grandes empresas. A causa é a falta para recursos de capital de giro, e para investimentos avançados. A inovação se daria por implantação de novos processos alternativos de produção e por técnicas de gestão (PICCININI, 1995).

O Banco Nacional Do Desenvolvimento (BNDS), em 2004 criou o BNDS-exim Pré-Embarque Empresa Âncora com a South Service Tranding S.A, a operação consiste no financiamento de até US\$ 8 milhões com o objetivo de estabelecer condições competitivas de financiamento às empresas do setor calçadista, a fim de diminuir as dificuldades enfrentadas pelas exportadoras de calçados decorrentes da forte concorrência internacional (BNDS, 2004).

Com tudo, o BNDS comprometia as micro, pequenas e médias empresas (MPMEs) a alavancar o apoio à exportação, sendo como primeiro destino os EUA, Europa, Canadá e América Latina. Por acompanhar a cadeia produtiva a South Service garante a qualidade dos produtos e aumenta a competitividade frente à concorrência dos calçados produzidos na China (Idem).

Segundo o BNDS (2004), neste sentido, MPMEs estariam voltando suas atenções ao modo de produção. Desse modo o programa, além de financiar cerca de US\$ 240 milhões no ano de 2006 a exportação foi um motivador as MPMEs que passaram a aderir a programas de qualidade em sua estrutura corporativa.

A indústria calçadista brasileira vem abrindo espaço no mercado internacional devido a grandes investimentos que vem realizando em design de produtos e marca (AMARAL, 2009).

As empresas que produzem calçados para exportação estão mais atentas às qualidades de seus produtos, uma vez que a diferenciação é apresentada como uma estratégia (ABICALÇADOS, 2013). 


\section{ADMINISTRAÇÃO DE EMPRESAS EM REVISTA}

CENTRO UNIVERSITÁRIO CURITIBA - UNICURITIBA - VOLUME 19 - NÚMERO 01/2019 -CURITIBA/PARANÁ/BRASIL - PÁGINAS 97 A 122 - DOI: 10.6084/m9.figshare.11338463 - ISSN: $2316-7548$

No inicio dos anos de 1970, uma parte da economia brasileira era desenvolvida tendo um mercado estruturado, com razoável distribuição de renda, nível baixo de desemprego e com baixo nível de inflação. Essa estabilidade foi abalada pelo fato desses padrões de crescimento terem se esgotado, e marcado pela internacionalização dos mercados, e em decorrência desse fator, uma instabilidade crescente no modo de produção (PICCININI, 1995).

A internacionalização de empresas tem ocorrido de diversas formas. Países como Estados Unidos, Alemanha, Japão, Suécia, entre outros, demonstram evoluções importantes em relação ao processo de internacionalização por meios do envolvimento com o mercado externo. Apesar das dificuldades enfrentadas, empresas de países em desenvolvimento também têm tido a capacidade de competir em meio a esse mercado global. No caso do Brasil, o processo de internacionalização ocorreu de forma lenta e tardia, porém algumas empresas brasileiras passaram por experiências significativas de evolução em direção ao mercado externo, principalmente após a abertura da economia nacional ocorrida no ano de 1990 (DALSOTO, 2007).

A partir de 1990, o processo de globalização começou a ser atrelada a forte desregulamentação, que gerou pressão para redução de preços, a velocidade que o mercado crescia. Criou-se um ciclo de inovações e a crescente influência de fluxos internacionais de capital mudaram profundamente os mercados estimulando à competição mundial (BANAS QUALIDADE, 2008).

A fim de contribuir no entendimento do processo evolutivo da internacionalização, Arruda et al. (19966 apud de DALSOTO, 2007), apresenta algumas ações estratégicas utilizadas na intenção de inserir uma empresa no ambiente internacional: 1) envolvimento com países que tenham reação a exportação, de forma a manterem vínculos a longo prazo; 2) criar vínculos com grandes corporações desenvolvidas no mercado externo, a fim de se tornar fornecedoras desses países; 3) agregar parcerias tecnológicas, que possam ser adaptadas e utilizadas; 4) expandir-se através de filiais que se beneficiem da matriz e de suas tecnologias; e 5) exposição internacional, que se dá a divulgação da marca e alianças

${ }^{6}$ ARRUDA, C. A.; GOULART, L.; BRASIL, H. V. Estratégias de Internacionalização: Competitividade e Incrementalismo. In: FUNDAÇÃO D. CABRAL. Internacionalização de Empresas Brasileiras. Rio de Janeiro: Quality mark, 1996. 


\section{ADMINISTRAÇÃO DE EMPRESAS EM REVISTA}

com empresas multinacionais, proveniente de expandir os produtos, também pode-se contar com a capacidade de expansão internacional através do fluxo de caixa proveniente da liderança no mercado interno.

Segundo Coutinho (19937 apud de COLTRO, 1966), as organizações tiveram que se aprimorar na busca por padrões produtivos, qualitativos e eficientes que envolvia a produção/operação, neste aspecto o que se exigia era uma boa estrutura, com comunicação clara e fluida, além da valorização dos recursos humanos no ambiente de trabalho. De maneira simples ou complicada boa partes das empresas tiveram que se ajustar a esse novo padrão, o qual garantiria a sua sobrevivência. A adoção de técnicas de qualidade, queima de linhas de produtos não competitivos, reestruturação administrativa e fluxo de produção mais eficiente, entre outras medidas marcaram o inicio do reflexo dessa nova mudança global.

De acordo com Killmann e Killmann (19918, apud de COLTRO, 1996) Devido o aprimoramento dos processos utilizados nas organizações, o surgimento de melhorias, envolvendo a produtividade, a eficiência e a eficácia, e a excelência para alcançar o sucesso, e principalmente a competitividade, os processos de melhoramento causaram uma compreensão do ambiente organizacional de maneira que as empresas evoluem gradativamente no decorrer dos anos.

Com a evolução das indústrias calçadistas, que sempre tiveram relevância para a economia brasileira, como: geração de emprego e renda no diferentes polos produtivos espalhados pelo país, o governo brasileiro em incentivo aos fabricantes de calçados ampliou a restrição dos calçados chineses no Brasil (EXAME, 2012).

Essa restrição foi imposta no ano de 2010, após uma investigação da qual o governo federal concluir que, a China exportava calçados fragmentados e os fabricava dentro do país. Essa forma de comercio desleal estava prejudicando a indústria brasileira, gerando alta nas importações, e agregando custos baixos aos calçados internacionais comercializados no mercado doméstico (ABICALÇADOS, 2013).

7 COUTINHO, L. Estudo da competitividade da indústria brasileira. In: Programa de apoio ao desenvolvimento científico e tecnológico, 1993, Campinas.

8 KILMANN, R. H.; KILMANN, I. Marking organizations competitive: Enhancing networks and relationships across traditional boundaries. San Francisco: Proquest Info \& Learning, 1991. 


\section{ADMINISTRAÇÃO DE EMPRESAS EM REVISTA}

CENTRO UNIVERSITÁRIO CURITIBA - UNICURITIBA - VOLUME 19 - NÚMERO 01/2019 -CURITIBA/PARANÁ/BRASIL - PÁGINAS 97 A 122 - DOI: 10.6084/m9.figshare.11338463 - ISSN: $2316-7548$

Dessa forma, até o ano de 2013 o Brasil estava protegido desse ciclo de importação desleal, devido à alta nos impostos de importação de insumos para calçados (Idem).

Outra forma de incentivo dado pelo governo nacional foi à redução da taxa de Imposto sobre Circulação de Mercadores e Serviços (ICMS), cessando a guerra fiscal entre os Estados, com prazo indeterminado, a alíquota do ICMS de 12\% passou para $7 \%$, assim, dando incentivos aos fabricantes a continuarem a buscar mecanismos para aprimorar a competitividade da indústria e fortalecendo o mercado doméstico (SINBIFORMA, 2013).

Com o fortalecimento do mercado doméstico, parcerias feitas entre industriários e associações sem fins lucrativos, tem gerado uma onda de inovação e destaque no mercado internacional, feiras que acontecem ao longo do ano no Brasil, como a Francal que aconteceu em julho de 2013, tem atraído diversos visitantes, com os objetivos focados em negócios. Gerando expectativas para as exportações a partir de um dólar mais valorizado (ABICALÇADOS, 2013).

De modo geral pode-se definir de acordo com a revista Banas Qualidade (2008, p.108) que a competitividade:

De uma organização é conseguida por ações constantes de melhoria na sua qualidade e produtividade. Esse princípio refere-se tanto as melhorias incrementais, quanto a revolucionária ou inovadora.

Neste sentido, competitividade relaciona-se com ações ao nível de capacidade tecnológica e administrativa empregada por empresas que estão evoluindo e fazendo parcerias internacionalizadas, perpassando a pesquisa e na busca de novas tecnologias como é o caso da indústria de calçados (PICCININI, 1995).

As transformações que vem ocorrendo no ambiente empresarial é um referencial ao futuro, as mudanças em movimento, às buscas por informações e tecnologias, mostram um investimento cada vez mais na qualidade e produtividade (GONÇALVES, 2000).

Dessa forma, com vista a enfrentar um dos principais gargalos do setor coureiro-calçadista brasileiro, a Associação Brasileira de Indústrias de Calçados (Abicalçados), promoveu no ano de 2013, reunião de alinhamento da cadeia produtiva do segmento para definição das demandas de formação e qualificação profissional do Programa Nacional de Acesso ao Ensino Médio e Emprego (Pronatec). O objetivo 
dessa reunião foi avaliar, num primeiro momento, as dificuldades enfrentadas pelos polos calçadistas do país, como a falta de mão de obra qualificada e o desinteresse quanto ao trabalho manual (ABILCAÇADOS, 2013).

Segundo o autor supracitado, uma das ações a serem estudas na reunião realizada pela Abicalçados é adotar estratégias diferenciadas para estimular a permanência das pessoas durante os cursos de capacitação. E estimular propostas atrativas para os futuros trabalhadores junto aos empresários da indústria calçadista. Pois, se nota que pelo fato dos trabalhadores se tornarem mais seletivos devido a essa capacitação, a permanência no chão de fabrica não compensatório sem que haja uma remuneração salarial mais justa, é preciso que os empresários se adaptem a essa nova realidade, revendo seus interesses em relação aos recursos humanos.

Contudo, a exploração do setor calçadista torna-se cada vez mais dinâmica no mercado externo, já que o Brasil possui uma perspectiva de expansão em longo prazo, com uma economia razoavelmente segura, é natural que incentivos de melhoramento em relação à mão de obra fosse interesse tantos dos industriários como do governo. Desta forma, os polos calçadistas brasileiros se tornam atrativos as empresas multinacionais (DELOITTE, 2012).

Para que as fusões garantam a competitividade no mercado internacional fazse necessário aderir novos mercados e assumir novos desafios. Usando como ordem as metas de reduzir custos, garantir inovação tecnológica, qualidade nos produtos, diversificação nos serviços e cumprir prazos estabelecidos. Porém, há uma preocupação no habito e na cultura de cada nação, que poderá ser um diferencial competitivo e garantirá o sucesso na identificação das necessidades e desejos de cada mercado internacional para a elaboração de estratégias e produtos de qualidade (GOLÇALVES e HAFFNER, 2008).

Neste sentido, as empresas têm como interesse em saber qual é a imagem que os países externos têm de suas organizações (CORRÊA, 2010).

De acordo com Giraldi et. al. (2008, p.24), “diversos estudos empíricos avaliam os efeitos do país para qual está se exportando produtos a partir de varias perspectivas. Em geral, admiti-se que a imagem do país exportador influencia as avaliações de produtos pelo consumidor e suas decisões de compra". 


\section{ADMINISTRAÇÃO DE EMPRESAS EM REVISTA}

Segundo o Verlech e Steenkamp (19999 apud de Giraldi et. al., 2008), essa avaliação pode acontecer devido à variedade de medidas e informações intrínsecas (que envolve a composição física do produto), extrínsecas (relacionadas ao produto, mas não corresponde a sua composição física), e por fatores culturais e ambientais.

Porém, não se pode deixar de resaltar que a imagem do Brasil a primeira vista é associada a esporte, carnaval, pobreza e miséria. O que de certa forma influencia na imagem dos produtos brasileiros exportados, verifica-se através da pesquisa realizada no ano de 2001, pela Confederação Nacional de Transporte (CNT), que os consumidores estrangeiros de 22 países avaliam os produtos brasileiros como sendo: 8,4\% não confiáveis, 46,3\% razoavelmente confiáveis e 12,5\% muito confiáveis (CNT, 2001).

Uma pesquisa realizada no ano de 2004, por estudantes da Universidade de São Paulo (USP), por meio de questionário enviado por e-mail a professores graduados da School of Economics Haarlem, Holanda, resaltou que a imagem do calçado brasileiro para o público jovem, ao qual foi segmento a pesquisa, indicou que: Em geral, os produtos brasileiros representam boa qualidade pelo que se paga, durabilidade e são tecnicamente avançados (Giraldi et. al., 2008).

Segundo o autor supracitado, o item que recebeu a pior avaliação referente à pesquisa realizada em 2004 na Holanda, foi o item relacionado à distribuição e comunicação de vendas. O que se indica que o Brasil precisa melhorar seus canais de distribuição e comunicação. Porém, a literatura internacional ainda reporta alguns efeitos sobre os países em desenvolvimento, assimilando a uma imagem catalisadora não pertencendo a um padrão de alta qualidade de seus produtos.

Apesar do Brasil ainda ser um país em desenvolvimento, a sua tecnologia já pode equiparar-se as tecnologias utilizadas por países desenvolvidos. A imagem do Brasil está em sétimo lugar na lista de países visto como tendo maior influencia positiva no mundo, segundo a visão de 21 nações do globo. A pesquisa realizada pela GlobeScan/PIPA para a rede de notícias British Broadcasting Corporation (BBC), do Reino Unido, mostrou que $46 \%$ dos estrangeiros veem a influencia do Brasil sendo como positiva, no ano de 2013. Entretanto, 18\% dos países veem a imagem do Brasil como sendo negativa (EXAME, 2013).

9 VERLEGH, P. W. J.; STEENKAMP, J. B. E. M. A review and meta analysis of country of origin research. v. 20, n. 5, Amsterdam: Journal of Economic Psychology, 1999. 


\section{ADMINISTRAÇÃO DE EMPRESAS EM REVISTA}

\section{CONCLUSÃO}

Buscou-se identificar como a imagem coorporativa das empresas calçadistas brasileiras é vista pelo mercado e verificou-se que as organizações do setor em questão têm a sua imagem coorporativa associada à gestão catalisadora de competitividade.

$O$ que justifica as empresas calçadistas brasileiras unirem interesse com instituições como a Abicalçado, o SENAI e o SEBRAI é necessidade de capacitação dos funcionários contribuindo para os processos de produção mais competitivos internacionalmente.

Neste sentido, investimentos em tecnologias, a busca pelas certificações que comprovem essa mudança na cultura organizacional através da Gestão da Qualidade e acesso ao conhecimento como forma de incentivos para redução de custos e métodos eficazes de vendas corroboram na eficiência desses processos.

Com a introdução e a prática da Gestão da Qualidade na estrutura organizacional das empresas calçadistas, o comprometimento de todos envolvidos aprimora a diminuição dos custos, o cumprimento de metas e a qualidade dos produtos oferecidos aos clientes.

Desta forma, verificou-se que a prática da Gestão da Qualidade pelas empresas calçadista brasileiras é valorizada pelo mercado e corrobora no processo de construção da imagem das empresas do setor.

\section{REFERÊNCIAS}

ABICALÇADOS. (2013) Mão de obra em pauta no setor calçadista. Disponível em: $<\quad$ http://www.abicalcados.com.br/site/noticias_detalhes.php?id=87\&titulo=mao-deobra-em-pauta-no-setor-calcadista> acessado em: 08 de agosto de 2013. Acessado em: 15 de julho de 2013.

Componentes de calçados terão Selo de Sustentabilidade. Disponível em: $<$ http://www.abicalcados.com.br/site/noticias_detalhes.php?id=48\&titulo=abicalcados -divulga-programa-origem-sustentavel> acessado em: 08 de agosto de 2013 
Francal recebe importadores de 63 países e estimula exportações de calçasdos.

Disponível em:

http://www.abicalcados.com.br/site/noticias_detalhes.php?id=86\&titulo=francalrecebe-importadores-de-63-paises-e-estimula-exportacoes-de-calcados $>$ acessado em: 08 de agosto de 2013.

Governo anuncia redução do imposto de importação para

insumos de calçados.

Disponível

em: $<$ <ttp://www.abicalcados.com.br/site/noticias_detalhes.php?id=100\&titulo=governoanuncia-reducao-do-imposto-de-importacao-para-insumos-calcadistas $>$ acessado em: 08 de agosto de 2013.

Made in Italy para brasileiros. Disponível em: <http://www.abicalcados.com.br/site/noticias_detalhes.php?id=81\&titulo=made-initaly-para-brasileiros> acessado em: 08 de agosto de 2013

Mercado internacional foi destaque da Francal. Disponível em:

<http://www.abicalcados.com.br/site/noticias_detalhes.php?id=83\&titulo=mercadointernacional-foi-o-destaque-da-francal> acessado em: 08 de agosto de 2013. AMARAL K. S. (2009), Estudo sobre a contribuição da informação contábil na gestão do capital de giro em, empresas calçadistas do Vale do Sinos. Disponível em: $\quad$ <http://www.lume.ufrgs.br/bitstream/handle/10183/ $19148 / 000$ 734166.pdf?sequence=1 > acessado em: 15 de abril de 2013.

AZEVEDO. A. J.; SOUZA. M. A.; MACHADO. D. G.; Desempenho econômico financeiro de indústrias calçadistas brasileiras: uma análise de 2000 a 2006. v.3, n.6, São Paulo, 2009.

BANAS QUALIDADE, (2008). Armadilha do nome “qualidade total” Disponível em: <www.banasqualidade.com.br> Acessado em: 31 de Julho de 2013.

BIEHL. K. A.; MOSELE. E. Análise de percepção do operário calçadista frente às formas tradicional, celular, e grupos de trabalho de organização da produção. São Paulo, 2003.

BLODORN. M.; SOARES. M. Qualidade: uma questão de sobrevivência para as organizações. s.1., 2011. 


\section{ADMINISTRAÇÃO DE EMPRESAS EM REVISTA}

BNDS (2004), BNDES Exim Pré-embarque Empresa Âncora. Disponível em: < http://www.bndes.gov.br/SiteBNDES/bndes/bndes_pt/Institucional/Apoio_Financeiro/ Produtos/BNDES_Exim/exim_pre_ancora.html> acessado em: 15 de agosto de 2013. CAMPOS, V. F. TQC Controle da qualidade total (no estilo japonês). 5a Edição. RJ: Bloch Editores S.A., 1992.

CARVALHO JUNIOR. Análise das exportações de calçados. Seminario Nacional sobre exportação de calçados, Novo Humburgo, 1984.

CARVALHO, M. M.; PALADINI, E. P. Gestão da qualidade total: teoria e casos. 5ำ Reimpressão. RJ: Elsevier, 2005. p. 31-264.

CNT.

Pesquisa

Mundial.

Disponível

em:

<http://www.cnt.org.br/Imagens\%20CNT/PDFs\%20CNT/PesquisaMundialPortugues. pdf> acessado em: 18 de agosto de 2013.

COLTRO A. (1996), A gestão da qualidade total e suas influencias na competividade empresarial. Disponível em: <http://www.ead.fea.usp.br/cadpesq/arquivos/C02-art04.pdf> acessado em: 28 de março de 2013.

CORRÊA, D. (2010), A construção da imagem corporativa de uma empresa de componentes para calçado através do representante comercial. Disponível em: < http://ged.feevale.br/bibvirtual/monografia/MonografiaDaianeCorrea.pdf> acessado em: 28 de março de 2013.

COSTA, A.; FLIGENSPAN, F. Avaliação do movimento de relocalização industrial de empresas de calçados do Vale do Rio dos Sinos. Porto Alegre,

SEBRAE/RS, 1997. Disponível em: < http://www.cad.cse.ufsc.br/revista/18/05.pdf> acessado em: 25 de maio de 2013.

CROSBY, Philip, B. Qualidade, falando sério. São Paulo, McGraw-Hill, 1990.

DALSOTO. F. O processo de internacionalização de empresas brasileiras do setor de componentes para couro, calçados e artefatos. s.1., 2007.

DELOITTE, (2012) Brasil competitive. Desafios e estratégias para a indústria de transformação. Disponível em: <http://www.deloitte.com/assets/DcomBrazil/Local\%20Assets/Documents/Ind\%C3\%BAstrias/Manufatura/livro_final.pdf> acessado em: 13 de agosto de 2013.

EXAME (2012), Setor calçadista pede fim de importações predatórias. Disponível em: <http://exame.abril/economia/noticias/setor-calçadista-pede-fim-de-importacoespredatoria?page=2> acessado em: 13 de agosto de 2013 . 


\section{ADMINISTRAÇÃO DE EMPRESAS EM REVISTA}

EXAME (2013), Empório Naka vende 35\% do capital para Lusobrastex. Disponível em:< http://exame.abril.com.br/pme/noticias/emporio-naka-vende-35-do-capital-paralusobrastex> acessado em: 19 de agosto de 2013.

Félix C. Jr. (2010), Instituições financeiras no Brasil. disponível em: $<$ http://www.deloitte.com/assets/Dcom- Brazil /Local \%20Assets /Documents/Estudos\%20e\%20pesquisas/Livro_portugues.pdf> acessado em: 25/04/2013.

FIEPB. Centro de tecnologia do couro e do calçado Albano Franco. Disponível em: <http://www.fiepb.com.br/senai/unidades/ctcc\%E2\%80\%8E> acessado em: 19 de agosto de 2013.

FRANCISCHI. A. S. N.; AZEVEDO. P. F. Estratégias das empresas do setor calçadista diante no novo ambiente competitivo: análise de três casos. Gestão de Produção, v.10, n.3, p.251-65. São Paulo, 2003.

G1. (2013), Exportações de calçados caem 6,5 em junho ante maio, diz associação.

Disponível

em:

<http://g1.globo.com/economia/negocios/noticia/2013/07/exportacoes-de-calcadoscaem-65-em-junho-ante-maio-diz-associacao.html> acessado em: 08 de agosto de 2013.

, Brasil amplia restrições a calçados da China. Disponível em: < http://g1.globo.com/mundo/noticia/2012/07/brasil-amplia-restricoes-a-calcados-dachina.html> acessado em: 08 de agosto de 2013.

Calçadistas de Franca SP importam maquina que imprime calçado em 3D. Disponível em: <http://g1.globo.com/sp/ribeirao-pretofranca/noticia/2012/11/calcadistas-de-franca-sp-importam-maquina-que-imprimecalcados-em-3d.html> acessado em: 08 de agosto de 2013.

GARVIN, D. A. Gerenciando a qualidade: a visão estratégica e competitiva. Rio de Janeiro: Qualitymark, 1992.

GIRALDI. J. M. E.; NETO. A. J. M.; CARVALHO. D. T. Efeito país de origem para calçados brasileiros. São Paulo, 2008.

GOMES M. T. S. (2009), A abertura econômica no brasil e suas implicações na indústria em cidades médias do oeste paulista. Disponível em: <http://www.seer.ufu.br/index.php/caminhosdegeografia/article/view/15937/8993> acessado em: 03 de abril de 2013. 


\section{ADMINISTRAÇÃO DE EMPRESAS EM REVISTA}

GONÇALVES, C.; HAFFNER, J. A. H. O setor calçadista no Rio Grande do Sul: uma análise da sua evolução recente. s.1.:S.n., 2008.

GONVALVES, J. E. L. (2000), As empresas são grandes coleções de processos.

Disponível em:

$<$ http://www.scielo.br/scielo.php?pid=S0034-

75902000000100002\&script=sci_arttext> acessado em: 24 de março de 2013.

GORINI, A.P.F. Panorama do setor moveleiro no Brasil, com ênfase na competitividade externa a partir do desenvolvimento da cadeia industrial.

GREMAUD, A. P., VASCONCElos, M. A. S., TONETO JÚNIOR, R. Economia Brasileira Contemporânea. Ed. Atlas, 4a․ Edição, São Paulo, 2002.

IBTEC (2009), BANCO DE DÚVIDAS SOBRE A INTERPRETAÇÃO DA NORMA NBR ISO/IEC 17025:2005

Disponível

em:

<http://www.redemetrologica.com.br/arquivo/laboratorial/0902\%20-\%20IBTEC\%20-

\%20ensaios\%20mecanicos\%20dez10.pdf> acessado em: 30 de julho de 2013.

JURAN, J. M. A qualidade desde o projeto. 3ª Edição. SP: Livraria Pioneira, 1992. LOWERY, C.M.; BEADLES, N. A.; CARPENTER, J. B. (2000) Recursos Humanos que compõem a Qualidade. Banas Qualidade, São Paulo.

MANOCO. F. F.; GUIMARÃES. V. N. Gestão da qualidade total e qualidade de vida no trabalho: o caso da Gerência de Administração dos Correios. Revista e Administração Contemporânea, v.4, p.68-70, Curitiba, 2000.

MIRANDA, R. L. Qualidade total rompendo as barreiras entre a teoria e a Prática. 2aㅡㄹㄷão. SP: Makron Books, 1994. p. 1-6.

NEVES, M. A. Modernização industrial no Brasil: o surgimento de novos paradigmas na organização do trabalho. Educação \& Sociedade, n. 45, 1993.

OLIVEIRA. R. O empresariado industrial e a educação brasileira. n.22. Rio de Janeiro, 2003

PICCININI V. C. (1995), Mudanças na indústria calçadista brasileira: novas tecnologias e globalização do mercado. Disponível em: $<$ http://www.lume.ufrgs.br/bitstream/handle/10183/19401/000300521.pdf?sequence= 1> acessado em: 14 de abril de 2013.

PIMENTA F. V. Avaliação das dificuldades da empresas da cidade de Birigüi na transição das Normar ISSO 9000:1994 para a 9000:2000. Birigui SP, 2004.

REIS, C. N. A indústria de calçados no Brasil. Notas preliminares, v.9, $\mathrm{n} \cong 8,2010$.

Revista Banas Qualidade Editora EPSE №196 SET/08 SP p.59 - 107 
RELATÓRIO CNPQ, (2010) Relatório de Gestão institucional. Disponível em: < http://www.cnpq.br/documents/10157/45688/relatorio_gestao_2010.pdf> acessado em: 28 de março de 2013.

SASHKIN, M. KISER, K. J. (1994) Gestão da qualidade total na prática. Rio de Janeiro, Campus.

SCHEFFER F. (2010), Vantagens da implantação de sistemas de gestão da qualidade. Disponível em: <http://www.ibmex.com.br/artigos/vantagens...pdf> acessado em: 15 de abril de 2013.

SEBRAE (2012), Selo atesta sustentabilidade do calçados. Disponivel em: <http://www.sebrae.com.br/setor/couro-e-calcados/sobre-couro-e-calcados/inovacaoe-tecnologia/196-24-selo-atesta-sustentabilidade-do-calcado-1/BIA_19624> acessado em: 23 de agosto de 2013.

SENTANIN, O. F. (2003), Gestão por processos em uma empresa de P\&D. Disponível em: <http://www.abepro.org.br/biblioteca/ENEGEP2003_TR0702_1473.pdf> SINBIFORMA. Informativo do sindicato das indústrias do calçado e vestuário de Birigui, São Paulo, ํํ 101, 2013

SINDICALÇADOS (2008), Dados do setor calçadista. Disponível em: <http://webcache.googleusercontent.com/search?q=cache:40DLr8tQAM0J:www.sind icalcados-es.com.br/Informa.doc $+\& c d=1 \& \mathrm{hl}=\mathrm{pt}-\mathrm{BR} \& \mathrm{ct}=\mathrm{clnk} \& \mathrm{gl}=\mathrm{br}>$ acessado em: 14 de maio de 2013.

SILVA, C. L. M.; FONSECA, V. S.,(2010), Competitividade organizacional: uma tentativa de reconstrução analítica. Disponível em: < http://www.scielo.br/pdf/rac/v14nspe/a03v14ns.pdf> acessado em: 14 de maio de 2013.

SILVA, P. A. P.; PAULISTA P. H.; TURRIONI, J. B. (2008) Avaliação do impacto da certificação iso9001:2000 no desempenho organizacional. Disponível em: <http://www.abepro.org.br/biblioteca/enegep2008_TN_WIC_070_499_11535.pdf> acessado em: 23 de agosto de 2013. 